\title{
GUINEA ECUATORIAL: \\ DESCOLONIZANDO NUESTRO IMAGINARIO COLECTIVO
}

\author{
POR \\ Justo Bolekia BolekÁ \\ Universidad de Salamanca
}

\section{AL PRINCIPIO DE LOS TIEMPOS}

Voy a decir dos cosas antes de meterme de lleno en el tema objeto de esta contribución. Primero, que soy una consecuencia de esta enculturación diglósica, es decir, la foránea, importada e impuesta, que entró en mí con sangre (por aquello de que "la letra, con sangre entra"), desde la escuela del maestro con la fusta o el látigo en alto. Sentarse bien, leer bien, escribir bien, sostener bien el pizarrín, etc., son algunas de las enseñanzas que fui asimilando en mi pueblo. Segundo, soy víctima de la des-enculturación que trataron de imponer nuestros dos referidos mandamases, al fomentar el culto a la ignorancia desde una política de proletarización ciudadana, en la que maestros y alumnos, padres e hijos, jefes y subalternos, etc., se convirtieron, de la noche a la mañana, en proletarios y braceros, incapaces de reaccionar debido a la violencia ejercida por el gobierno.

Aprendí a leer. Pero a mi edad no puedo presumir haber leído mucho. Pero algo he hecho y aprendido, debido a mi acuciante necesidad de colmar mis carencias y las de allegados y extraños, aunque algunas veces dudara de la veracidad o viabilidad de lo que estuviera leyendo. Y todo esto como consecuencia de mi pluri-enculturación, yendo pendular y permanentemente de la sociedad mental y material de los ex-colonizadores y vencedores a la sociedad también mental y material de los ex-colonizados vencidos, esta última caracterizada por el sufrimiento inflingido por extraños y próximos, todo ello en beneficio de aquellos que se creen dueños y señores de Guinea Ecuatorial y de los guineoecuatorianos. Segundo, a pesar de tantas y tantas lecturas, unas veces voluntarias y otras veces solicitadas, me encuentro sustancialmente desubicado etnoculturalmente hablando, porque desde que concluyó mi inicial enculturación autóctona, he sido objeto de una transformación integral que ha hecho de mí, y de muchas otras personas, una imagen incompleta de la sociedad española o guineoecuatoriana indecisa.

Como ha ocurrido con muchísimos africanos, todas mis lecturas han ido configurando mi "personalidad" o identidad confusa e inasible, con mis miedos, mis conflictos y traumas, mis deseos callados, mis huidas, etc., de tal manera que hablar de la 
descolonización de nuestro imaginario colectivo me obliga a cuestionar ciertos referentes hoy considerados inherentes a la inestable, calamitosa, confusa y occidentalizada idiosincrasia guineoecuatoriana. De África parece que solamente nos queda el nombre porque, se mire por donde se mire, de norte a sur y de este a oeste, el continente africano vive sumido en una esquizofrenia acusada que se manifiesta en todos los niveles de sus sociedades indefensas, sus culturas desmanteladas, sus horizontes indefinidos, sus generaciones desorientadas, etc., porque la pretendida homogeneización que nos han querido (y quieren) imponer a nivel étnico, político, cultural, etc., no triunfó y choca hoy contra esta anarquía cultural que subyace en nuestra conciencia colectiva y en la solidaridad que nos caracteriza como pueblos africanos.

\section{El imaginario colectivo de África}

Quizá deberíamos primero tratar de definir qué debe o puede entenderse por imaginario colectivo de África. Estamos en la era de los motores buscadores y de la cibernética, algo que nos ha permitido comprobar que en la página web http://buscon. rae.es/drael/, la palabra "imaginario" presenta la acepción siguiente:

(Del lat. imaginarius). 1. adj. Que solo existe en la imaginación.

Siempre nos han dicho y convencido de que lo que existe en la imaginación no es real. Esto nos permite hablar hoy de dos situaciones incompatibles. En primer lugar, siempre hemos considerado real todo el acervo cultural que ha asimilado, asumido y almacenado en su memoria el africano como resultado de su enculturación etno-céntrica más remota. En segundo lugar, también hemos considerado real la enculturación impuesta por los colonizadores europeos, algo que también hemos asumido y almacenado en nuestra psique, y que ha construido en nosotros como africanos unas vivencias y unos sueños alejados de nuestra propia realidad empírica. Sin embargo, este hecho real acentuado nos traslada a una doble orientación para retratar objetivamente nuestra conciencia de las cosas y los hechos. Se trata de una realidad asentada en nuestra memoria, construida desde los aparatos ideológicos del Estado importado e impuesto, y cargada tanto de una ficción identitaria como de una conciencia protegida por un imaginario desprovisto de modelos autóctonos. Estas dos realidades han ignorado al africano como ser colectivo, profundamente relacionado con una familia horizontal, una comunidad, una etnia, etc. Cada uno de estos grupos cuenta con sistemas singulares de enculturación, sin que esto signifique que hablemos de compartimentos estancos, ya que existe un fondo cultural común, compartido por todos los miembros de una familia, una comunidad o una etnia. Basándonos en la Oralidad (u Oratura: dominio de la palabra), el hecho de que encontremos elementos comunes inter-étnicos (en cuanto a la percepción cosmogónica, a determinados personajes social y religiosamente relevantes, a ciertas funciones inherentes

Revista Iberoamericana, Vol. LXXX, Núms. 248-249, Julio-Diciembre 2014, 1099-1116 ISSN 0034-9631 (Impreso)

ISSN 2154-4794 (Electrónico) 
a cualquier proceso de formación, etc.) significa que ha habido una construcción tácita de la conciencia colectiva interafricana antes de que los colonizadores llegaran y ejercieran su violencia en todo el continente africano, algunas veces ayudados, lamentablemente, por determinados y contados africanos. ¿Es quizá esta conciencia colectiva interafricana lo que debemos entender por imaginario colectivo africano?

Esta rápida visión retrospectiva nos remite a un imaginario (anhelos y sueños de cualquier ser humano) autóctono de todos los pueblos de África en la etapa precolonial. La aprehensión de las identidades colectivas africanas permite que hablemos de tres esferas: En primer lugar, la esfera de las imaginadas o recordadas conductas ancestrales y endonormativas, adquiridas en el seno del grupo etnocultural a través del proceso de enculturación. Son conductas explicitadas en hechos tan concretos y humanos como la convivencia o socialización del individuo (su agrupación según vínculos consanguíneos, intereses económicos, proyectos militares, alianzas declaradas, etc.), el trabajo (representado por el desbroce, la posesión de hazas, el cultivo de la tierra, la caza para el consumo familiar, la artesanía funcional y decorativa, la pesca para el consumo familiar), el ocio (con sus manifestaciones culturales y cuyo objetivo era el fortalecimiento de los vínculos sociales y comunitarios) y la relación del hombre con el más allá (búsqueda del equilibrio entre el hombre y su entorno o naturaleza, o su intento por comprender el sentido de su propia existencia, etc.). Evidentemente, estamos ante la soberanía plena del africano.

En esta primera esfera situaremos los conocimientos mínimos necesarios para la existencia de cualquier animal, sea o no humano, sólo o acompañado. Estamos hablando de:

1. La procreación como un acto biológico no controlado por la conciencia y necesario para la continuidad de cualquier especie.

2. La alimentación como una necesidad fisiológica que debe ser satisfecha para garantizar la existencia y el desarrollo orgánico.

3. La salud física, necesaria para mantenerse con vida y luchar contra las adversidades internas (del propio organismo) y externas, $\mathbf{y}$ espiritual, relacionada con aquellas vivencias que escapan del control humano, y que necesitan del concurso de personajes específicos como el curandero, el adivino, el hechicero, etc.

4. La defensa, fundamental para responder eficazmente a las agresiones externas o internas al grupo.

5. La transversalidad vinculada, es decir, aquellas experiencias socio-culturales que viven los miembros de una familia, una comunidad, una etnia, etc.

Por muy inverosímil que parezca, la evolución de los seres humanos ha desarrollado otros conocimientos que se han vuelto también fundamentales para la existencia. Estamos hablando de:

a) La religión y las creencias con las que se buscaba (y se busca) dar sentido a la inexplicable y absurda existencia, desde una visión puramente creacionista (que busca el sentido de la existencia desde las religiones y el pensamiento mágico, ilógico eirracional).

Revista Iberoamericana, Vol. LXXX, Núms. 248-249, Julio-Diciembre 2014, 1099-1116 ISSN 0034-9631 (Impreso)

ISSN 2154-4794 (Electrónico) 
b) La tecnología artesanal o pretecnología, y con la que se trataba de mejorar las técnicas para el logro de determinados fines.

c) La reflexión y el análisis que son inherentes a la visión evolucionista (que busca el sentido de la existencia desde la ciencia y el pensamiento lógico y racional).

Todos estos conocimientos se encuentran recogidos en el término CULTURA, definido por el antropólogo británico Edward B. Tylor en su obra La civilisación primitiva como el "conjunto complejo que incluye el conocimiento, las creencias, el arte o las técnicas, la moral, la ley, las costumbres y cualquier otra facultad y hábito que el hombre adquiere como miembro de la sociedad" (Mbocké).

En segundo lugar, hablaremos de las conductas modernas y exonormativas, es decir, adquiridas en la escuela, por obligación o imitación, como consecuencia del choque frontal programado por los blancos contra los negros de todo el mundo y la historia. Son esas conductas con las que los africanos se apartan psicológica y socialmente de sus realidades etnoculturales. Fueron protagonistas de tal desastre africano los portugueses, los españoles, los ingleses, los franceses, los belgas, los alemanes, los italianos, los holandeses, etc., quienes se valieron de determinados aparatos ideológicos (representados por la Iglesia, la Escuela, el Comercio, el Ejército, el Internado, los Medios de Transporte, los Lugares de Trabajo, etc., y las Armas) para transformar al hombre africano, a la mujer africana, al África negra en general, aprovechando su diversidad etnocultural y sociopolítica, así como su falta de cooperación como consecuencia del debilitamiento demográfico y psicológico.

De los tres conocimientos mínimos necesarios tenemos que añadir, primero, el consumo a la alimentación, como el deseo de obtener aquellas materias con las que colmar una necesidad material o, más bien, mental. Se trata de un consumo ajeno a los hábitos alimentarios primarios de los africanos de este periodo. Estamos hablando de productos como los diamantes, el petróleo, el coltan, el oro, la madera, el uranio, el fosfato, el café, el algodón, el cacao, el gas, etc. Y segundo, la admisión o transmisión de imágenes europeas en las aldeas, los poblados, los barrios, las escuelas, etc., con las que los africanos fueron construyéndose referentes ajenos a su idiosincrasia, imaginándose un mundo blanco con protagonistas negros, o un mundo negro con protagonistas negros pero con máscaras blancas. Evidentemente, este desvío produjo una inestabilidad cognitiva por parte de los africanos, a raíz del caos y confusión que causó en ellos la incertidumbre de verse derrotados sin haberles sido declarada una guerra, y sin ni siquiera darles tiempo para luchar.

En tercer lugar están las conductas contemporáneas que son consecuencia de las anteriores adquisiciones y también fruto de los referentes mediáticos que definen el espacio africano. Nos referimos a todo lo que gira en torno a los establecimientos de los burger kings, mcdonalds, los dibujos animados de Walt Disney, los cuentos populares europeos, kentucky fried chickens, coca-cola, teléfonos móviles, emepécuatro, aipods, etc.

Revista Iberoamericana, Vol. LXXX, Núms. 248-249, Julio-Diciembre 2014, $1099-1116$ ISSN 0034-9631 (Impreso) 


\section{El IMAGINARIO COLECTIVO DEL GUINEOECUATORIANO}

Eluso que hacemos de este gentilicio obedece a razones de coherencia discursiva. Si el país se llama Guinea Ecuatorial, lo más normal es que su gentilicio sea guineoecuatoriano (o guineoecuatorial). Sin embargo no es así muchas veces, ya que hasta llegar a este gentilicio extra-normativo, se ha pasado por muchos otros gentilicios:

Etapa Pre-colonial:

Negritos o Morenos (annoboneses [o ámbös], bujebas [o bisíös], bubis [o aböbéë, o batyö], pamues [o fangs], fernandinos [o kriós], combes [o ndowès], etc.).

\section{Etapa Colonial:}

Guineanos o Negros/Negritos/Morenos (annoboneses, bubis, bujebas, pamues, fernandinos, combes, etc.).

\section{Etapa Post-colonial:}

Guineanos (annoboneses, bisíös, bubis, fang, kriós, ndowès, etc.), Ecuatoguineanos y Guineoecuatorianos.

Los elementos etnoculturales que subyacen en nuestra inicial guineoecuatorianeidad (en proceso de construcción) se refieren a la aportación etnocultural indirecta que es aceptada por todos nosotros como miembros de una comunidad política, y no nacional, ya que esta última puede y debe entenderse como la posesión y uso de una misma lengua autóctona, la convicción de practicar los mismos ritos y la certeza de tener un mismo antepasado. Y no se dan estas condiciones. En este sentido, la guineoecuatorianeidad que queremos convertir en endoglósica se apoyará sobre elementos tales como los que hemos encontrado en cada una de las etnias que conforman el Estado de Guinea Ecuatorial. A través de estos elementos específicos de cada etnia serán buscados aquellos que nos son comunes y que nos unen. Sirvan como muestra los elementos que aparecen a continuación y que son inherentes a cada una de las etnias definidas de Guinea Ecuatorial:

\footnotetext{
Ámbös:

Institución Consistorial: Viyil.

Manifestación Cultural: Mamae, Kumbe.

Lengua de la Etnia: Fa d'Ambo.

Lengua de Relación: Español, Pidgin-English, etc.

Bubis:

Institución Consistorial: Wetya, Tyóbbo.

Jefatura: Böhítáari, Bötúku.

Manifestación Cultural: Katyá, Bölëbó, Sihíri.
}

Revista Iberoamericana, Vol. LXXX, Núms. 248-249, Julio-Diciembre 2014, 1099-1116 
Religiosidad: Ruppé (Dios), Mörímò (intermediario entre los vivos y los muertos, conocedor, sanador), Tyiántyo (hechicero).

Lengua de la Etnia: Ëtyö, Ëböbéë.

Lengua de Relación: Español, Pidgin-English, etc.

Fang:

Institución Consistorial: Abaá.

Jefatura: Nkúkúmá.

Manifestación Cultural: Ndongmba, Mokom.

Religiosidad: Nzama (Dios), Nguendáng (curandero), Mesamélúgu (hechicero).

Lengua de la Etnia: Fang.

Lengua de Relación: Español.

Ndowès:

Institución Consistorial: Njoe.

Jefatura: Mpóló.

Manifestación Cultural: Mebongo, Mekuyo, Mbaya.

Religiosidad: Añambe (Dios), Nganga (curandero), Ngondye (hechicero).

Lengua de la Etnia: Ndowè.

Lengua de Relación: Español.

Estas cuatro etnias mantienen todavía algunos de sus elementos identificativos. Con ellos se representan, a muy duras penas, dentro de la guineoecuatorianeidad política, debido a la función deculturizante que las escuelas españolas han tenido en Guinea Ecuatorial, las cuales siguen sin estar todavía nacionalizadas en cuanto a sus contenidos, material, formación, etc., como en la mayoría de los países africanos. En resumidas palabras, no existe una soberanía endocultural desde que esta escuela importada e impuesta sustituyó el contexto iniciático.

Desde la etapa colonial efectiva(1843) hasta la actualidad(2009), cada una de las etnias del país ha vivido ciertos procesos de asimilación progresiva de la guineoecuatorianeidad de la otra, muchas veces de manera inconsciente, al no disponer de espacios institucionales desde los cuales se pueda informar y enseñar a los guineoecuatorianos a asumir su identidad política desde su condición etnocultural. Esta ausencia de espacios compartidos y definitorios, o de espacios en los que cada etnia guineoecuatorianizada disponga de la libertad de determinar su destino dentro del conjunto, se debe al secuestro y a la patrimonialización de la identidad guineoecuatoriana (o guineana) o a la anulación de las identidades etnoculturales por parte de nuestros gobernantes.

\section{CONFLICTO ENTRE EL PASADO CULTURAL Y EL PRESENTE IMAGINARIO}

Las tres esferas que hemos visto más arriba, determinan todos los espacios de actuación del hombre africano. Desde lo estrictamente político a lo socio-cultural, pasando por lo literario, lo religioso, etc., existe una muy remota necesidad imperiosa de desprenderse 
de este poder del hombre negroafricano sin ubicación socio-cultural y sin etnia, opresor y represor, mentalmente separado de su esencia, y responsable directo de la permanente profanación de la sacralidad cultural de todo un continente, con sus gentes, sus costumbres, sus normas, etc., o lo que queda de ello. La agresión y el ultraje infligidos a la tierra de nuestros ancestros provocan una profunda regresión al pasado, a ese mundo de los secretos, para tratar de reconocerse en ese momento y rescatar, si es posible, aquellos elementos que pudieran servir para dar contenido a nuestra existencia. Personajes políticos como Kwame Nkrumah (Ghana), Steve Biko(Sudáfrica), Patrice Lumumba(R. D. del Congo), Thomas Sankara (Burkina Faso), etc., o historiadores y hombres de letras (productores culturales) como Pathé Diagné (Senegal), Joseph Ki-Zerbo (Burkina Faso), Tchicaya U Tam'Si (Congo-Brazzaville), Cheikh Hamidou Kane (Senegal), Amadou Hampâté Bâ (Malí), Ferdinand Oyono (Camerún), Ahmadou Kourouma (Costa de Marfil), Djibril Tamsir Niane (Guinea Conakry), Cheik Anta Diop (Senegal), etc., soñaron con reconstruir la conciencia colectiva de los africanos y liderar la transformación que se necesitaba para descolonizar el imaginario nocivo del que se estaban (y se están) apropiando inconsciente y permanentemente todos los africanos. Lamentablemente, los antihéroes de este proyecto fueron pronto entronizados y llevados a ocupar amplios espacios de poder, poniendo fin a los sueños de millones de africanos. Aquí tampoco podemos hablar de una soberanía cultural, a pesar de los muchos intelectuales y librepensadores que ha conocido (y conoce) África. En temas como éste (la enseñanza y construcción cognitiva), el monopolio de los Estados heredados de la colonización impide que los grandes pensadores participen en el diseño de la conciencia colectiva general.

Deteniéndonos un poco en esta sacralidad, diremos que África se debate entre cinco culturas religiosas, como son la tradicional-ritualista, interesadamente denominada "animista" (término acuñado por Edward Tylor en 1866, y hoy utilizado para desprestigiar la religiosidad tradicional africana dentro y fuera de África), la musulmana exógena, transmitida en lengua árabe, la judaica exógena y de limitada presencia en África, la cristiana también exógena y más reciente, impuesta a los africanos por medio de la enculturación socio-educativa, con la invención posterior de la inculturación (una especie de simbiosis y tolerancia entre lo católico y lo "animista"), y la laica, llevada a África por sus mismos practicantes. Cada una de estas cinco culturas religiosas se define por la configuración interna o externa que llega a esculpir en cada uno de sus receptores, tanto a nivel moral como comunicativo, interrelacional, estético-literario, etc.

Todo lo dicho nos permite afirmar que la construcción de la conciencia colectiva africana, o del imaginario colectivo, abarca muchos frentes: el religioso, determinado por la forzada cohabitación de las cinco prácticas religiosas con las que se enfrenta el africano, y explicitado en el uso de términos despectivos hacia su propia esencia espiritual. El africano hace suyos los significados que contienen términos como animismo, hechicería, prácticas brujeriles, vampirismo, canibalismo o antropofagia, etc.; el socio-cultural,

Revista Iberoamericana, Vol. LXXX, Núms. 248-249, Julio-Diciembre 2014, 1099-1116 ISSN 0034-9631 (Impreso)

ISSN 2154-4794 (Electrónico) 
con el uso de términos también despectivos como bantú, subsahariano, nombres de países sin ninguna razón étnica, etc.; el lingüistico-comunicativo, con lenguas oficiales extranjeras, normas de comunicación ajenas a los protocolos culturales étnicos, etc.; el tecnológico-funcional, con el uso de utensilios importados, unas veces necesarios y otras no, etc. Todo esto demuestra que carecemos de una soberanía religiosa autóctona, comunicativa (ya que utilizamos sistemas "aprendidos" en la escuela), tecnológicofuncional, etc.

Debemos añadir también que la influencia y el propósito de estos personajes occidentales y occidentalizados en la configuración u homogeneización socio-cognitiva de los africanos sirvieron para desmantelar las culturas de este continente, y enfrentarlas a aquellas cuyos propietarios llegaron de allende los mares. La separación cultural entonces determinada sigue hasta hoy, según Burhan Ghalioun (43), tal como podemos observar:

\begin{tabular}{|l|l|}
\hline \multicolumn{1}{|c|}{ Colonizadores } & \multicolumn{1}{c|}{ Colonizados } \\
\hline Culturas dominantes & Culturas dominadas \\
Culturas productoras de sentido & Culturas frustrantes \\
Cultura de los ciudadanos & Culturas de los indígenas \\
Culturas agresivas & Culturas pasivas \\
Culturas creativas & Culturas estériles \\
Sociedades cohesionadas & Sociedades marginadas y desestructuradas. \\
Culturas acrolectales y de las élites & Culturas basilectales (populares) \\
\hline
\end{tabular}

En esta destrucción y desmantelamiento de las sociedades africanas también participaron (y siguen participando) los mismos africanos. Estamos hablando de los antihéroes antes aludidos, grandes dictadores que ha parido dicho continente, y que han frenado cualquier intento de reencuentro y reconstrucción de las identidades africanas, apoyados siempre por sus valedores occidentales (Estados Unidos de América, Francia, Reino Unido, Canadá, Italia, Alemania, España, Japón, etc.) y no occidentales (China, Rusia, etc.), o que diseñan y ejecutan programas bélicos contra las poblaciones que dicen gobernar. Estamos hablando de personajes como Idi Amin Dada (Uganda), Jean Bedel Bokassa (República Centroafricana), Joseph-Désiré Mobutu (Congo-Zaire), Francisco Macías Nguema (Guinea Ecuatorial), Sékou Touré (Guinea-Conakry), Hissène Habré (Chad), Eyadema Gnassingbé (Togo), etc., o los nuevos dictadores y militares en trajes civiles, como Joseph Kabila (R. D. del Congo), Teodoro Obiang Nguema (Guinea Ecuatorial), Denis Sassou Ngueso (R. P. del Congo), etc., en cuyas constituciones -en parte hechas a su imagen y semejanza-se recogen artículos que prolongan su inmunidad aun después de muertos. Sería sumamente interesante estudiar psicológicamente a estos dirigentes nuestros para entender la razón de sus continuos atropellos y los muchas 
violaciones de derechos humanos. Si todo pasado se refleja en el presente, es obvio que estos mandamases y agresores de las identidades etno-culturales africanas estén únicamente reproduciendo lo que en su día aprendieron o mamaron.

\section{LITERATURA E IMAGINARIO COLECTIVO AFRICANO}

Las sociedades occidentales están agotadas. Necesitan nuevas fuentes de inspiración y referencia de las que nutrirse para renovarse culturalmente si no quieren perecer. En lo que respecta a la literatura, dentro de este imaginario elitista acrolectal de los vencedores, y del también imaginario, pero popular y basilectal de los vencidos, observamos dos tipos de procedimientos: el desplazamiento de la Oralidad u Oratura (con un significado rotundo, cual es "la dominancia de la palabra"), o su sustitución por la literatura escrita (una verdadera dictadura de las letras). En cada uno de nosotros los africanos, ambas (la Oralidad u Oratura y la Literalidad o Literatura), con la proyección interior (o la internalización) que cada uno haga de ellas, sirven para rememorar o recrear la tragedia incuestionable de los hechos históricos acaecidos en cualquier parte de África en general y de Guinea Ecuatorial en particular.

Pero como en cualquier realidad condensada, aunque sea literaria, en estos hechos tan trágicos, todos hemos participado, aunque más los blancos que los negros, más los gobernantes (blancos o negros) que los gobernados, según las evidencias incuestionables de la historia negra. En primer lugar, los blancos (y/o españoles) como agresores externos y dominadores de África en todos los niveles, sobre todo desde el momento en que son ellos, con sus instituciones, quienes validan y rechazan todo lo que pueda hacer, inventar o proponer un africano. En este sentido, estos agresores deben seguir siendo considerados atentos controladores del hombre africano en cuerpo y alma. En cuerpo porque el africano viste generalmente como el blanco, cultiva su cuerpo con los productos fabricados por y para los blancos, quiere vivir como el blanco ¿por qué no?, comer como el blanco, etc. En alma porque piensa como el blanco y le imita, en parte debido a la imposición de conductas y creencias religiosas ajenas a las culturas africanas. En segundo lugar, los africanos y/o guineoecuatorianos participaron como agresores de sus propias realidades en su triple vertiente:

1. Los legitimados poderdantes y poderhabientes (gobernantes) de nuestro continente, se convirtieron en agresores internos africanos y guineoecuatorianos, y en alumnos aventajados de sus maestros blancos, desde el momento de actuar como éstos y ser la fiel réplica de los colonizadores (algo que demuestra una adecuada aculturación y una des-enculturación). La negación del otro, su conversión desde los patrones socioculturales propios, propicia su alienación.

2. La población víctima de esta doble agresión y atrapada en esa disglosia sociopolítica impuesta por sus gobernantes, y manifestada en la doble fantasía espiritual y altamente

Revista Iberoamericana, Vol. LXXX, Núms. 248-249, Julio-Diciembre 2014, 1099-1116 ISSN 0034-9631 (Impreso)

ISSN 2154-4794 (Electrónico) 
rentable para sus opresores. Aquí no podemos evitar hablar de la fantasía orfeica o epimeteica (búsqueda de la solución a tantas carencias mediante la regresión y el constante viaje o mirada al pasado), y de la fantasía onírica que se nutre de la ensoñación o utopía de la población oprimida y chantajeada. Ambas fantasías son promovidas, tal como hemos indicado, desde el poder, llámese interno (africano o guineoecuatoriano) o externo (colonizador europeo o español), y con la participación de la Iglesia oficial, dando lugar al abismo generacional provocado por la instrucción recibida por los hijos desde la escuela europea o española en África o en Guinea Ecuatorial. Aquí debemos también mencionar la conversión interior de los propios africanos y guineoecuatorianos, o la aculturación de la que fueron y son objeto, frenando cualquier intento de sublevación, exigencia o reclamo durante muchos siglos.

3. Los escritores africanos y guineoecuatorianos, muchas veces convertidos en observadores y denunciantes de estas realidades. Esto lo hacemos desde tres visiones:

- Una mirada atenta al pasado (proceso orfeico o epimeteico), con la que se pretende realzar aquellos rasgos que han sido esenciales en la construcción de nuestro imaginario, y también para tratar de entender el futuro.

- Una mirada consciente al futuro (proceso prometeico) para contemplar la destrucción de nuestras identidades en este presente no definido y tan violentado.

- Una mirada hacia uno mismo (proceso fetal y umbilical) para huir de esta tragedia incuestionable de los hechos sangrientos que jalonan nuestra historia pasada y presente, fruto de este choque cultural.

Todo lo anterior nos permite hablar de una colonización integral del imaginario del africano en general, y del guineoecuatoriano en particular. Además, se trata de una colonización no concluida y que condiciona hoy las realidades africanas, cuyos gobiernos son incapaces de promover cambios que permitan la reanudación de sus historias interrumpidas. ¿Quién no ha oído hablar del sueño africano desde los gobiernos importados, con sus organizaciones gubernamentales panafricanas como la Unión Africana (con su Parlamento, su Comisión, el NEPAD, la Diáspora Africana como Sexta Región, etc.)? Pero una cosa son los decretos y resoluciones que aprueban nuestros gobernantes, y otra bien distinta, su aplicación. En resumen, existe una evidente ruptura entre el poder africano importado, actual y vigente, y las sociedades civiles africanas, mentalmente colonizadas y políticamente malgobernadas desde hace muchos años. Unos y otros, malgobernantes y malgobernados, todos tratamos de vivir a imagen y semejanza del blanco (con la debida distorsión), porque inconscientemente hemos renegado de nuestras esencias culturales para vivir con el imaginario blanco, con la conciencia colectiva occidental blanca como algo propio, sencillamente porque nuestra “enculturación académica, mediática, religiosa, popular, gastronómica, etc.” se basa en el modelo occidental blanco. Nuestra conciencia e imaginario colectivo como africanos ha sido diseñado por los promotores culturales de las sociedades colonizadoras. 
El contacto con el hombre blanco, con la sociedad occidental blanca, nos ha hecho ver que la identidad colectiva africana actual es un invento de la colonización, que se ha ido configurando desde la activación de todos los aparatos ideológicos, llámense escuelas, internados, campamentos militares, iglesias, tiendas, medios de comunicación, trabajos forzosos con capataces blancos o negros ávidos de méritos, películas con espacios y protagonistas blancos, etc.

Nos han enseñado a ser unos africanos desvirtuados, psicológicamente derrotados, desracializados, interesadamente deculturados (o desalfabetizados) - debido a la rápida pérdida de aquello que les fue transmitido-, y con el firme propósito de enseñarnos a renegar de nuestra interesadamente denominada identidad étnico-cultural. No tenemos derecho a hablar de nuestra historia calamitosa, ni de las atrocidades que se han cometido contra nosotros. Somos, o nos hacen ser más occidentales que africanos. Vivimos como quieren que vivamos y la historia que vivimos no es la nuestra. Es una historia que nos ignora, sencillamente porque no la hemos escrito nosotros, no la hemos hecho nosotros ni hemos participado en su diseño. En la mente colectiva del occidental blanco, el africano no existe como un igual. Se trata de un individuo que se ha convertido en una invención de los miedos y los conflictos del occidental blanco. El discurso oficial y mediático sobre el africano recurre a los tópicos de la conciencia colectiva blanca para justificar una explotación interesada.

Pero no deberíamos olvidar que desde que el africano se hizo propietario y también dueño de la lengua de su colonizador, se ha servido de ella para tratar de describir su realidad empírica, concretada en el resto de sus tradiciones, sus mitos, su entorno, etc., o para denunciar aquellas injusticias que nadie se atreve a denunciar, ni tan siquiera referir en sus conversaciones. La utilización de una lengua exonormativa o exoglósica en la producción literaria y cultural de los africanos contribuye a incrementar más aún el contenido de su confuso imaginario colectivo. Las literaturas africanas, todavía muy ricas en referentes, pero que estamos agrediendo, o matando, debido al continuo uso de la traducción de estas literaturas a las lenguas europeas, se han quedado en los únicos contextos en los que podemos encontrar aquellos elementos culturales con los que reconstruir nuestro imaginario colectivo.

\section{TRANSGRESIÓN DEL IMAGINARIO COLECTIVO AFRICANO}

Después de todo lo dicho, llega la pregunta que debimos hacernos y contestar antes de iniciar nuestra larga exposición: ¿qué es el imaginario colectivo de África? ¿Por qué tenemos que descolonizarlo? Se trata de algo que han inventado los blancos para los africanos de manera deliberada. De lo contrario, no leeríamos únicamente obras literarias escritas por occidentales blancos para occidentales blancos. Pero a nosotros nos exigen escribir desde la cultura dominante, con realidades y personajes blancos y universales,

Revista Iberoamericana, Vol. LXXX, Núms. 248-249, Julio-Diciembre 2014, 1099-1116 
porque el universo está diseñado por los blancos y no incluye a los negros, a pesar de haber incorporado al rey negro Baltasar entre los Reyes Magos, o de haber tenidosdos Secretarios de Estados negros en USA (Colin Powel y Condolezza Rice) gracias al presidente George W. Bush, o que el presidente de los Estados Unidos de América se llame Barack Hussein Obama, hijo de un keniano negro y de una estadounidense blanca, condenado a vivir en una esquizofrenia socio-emocional: negro para los blancos, y blanco para los africanos del África profunda.

En la transgresión de nuestro imaginario colectivo africano, encontramos testimonios como el que nos ofrece Aurélien Gnahoui, que no tiene desperdicio. Se trata del discurso de bienvenida que pronunció el ministro belga Jules Renquin en 1920 para los misioneros que trabajaban en el Congo, al término de la pacificación de África, una pacificación que hoy entendemos como la derrota militar del africano en una guerra unilateral que se saltó todos los protocolos, en una África sin guías y debilitada:

Reverendos padres y queridos compatriotas, bienvenidos a nuestra segunda patria el Congo Belga. La labor a la que estáis invitados a tomar parte resulta muy delicada y requiere mucho tacto. Padres, es cierto que venís a evangelizar. Pero esta evangelización debe inspirarse en nuestro gran principio: todo y ante todo por los intereses de Bélgica.

El objetivo primordial de vuestra misión no es enseñar a los negros a conocer a Dios. Ellos ya le conocen. Hablan y se someten a un Nzambé o a un Nvindi-Mukulu, y qué sé yo. Saben que matar, robar, calumniar e injuriar es malo.

Tened el valor de reconocerlo, no venís a enseñarles lo que ya saben. Vuestro papel consiste, básicamente, a facilitarles la tarea a los administradores y a los empresarios. Esto quiere decir que interpretaréis el evangelio de la mejor manera posible para que sirva a nuestros intereses en esta parte del mundo.

Para lograrlo, procuraréis, entre otras cosas:

Que nuestros salvajes se desinteresen por las riquezas materiales de su tierra, para evitar que al interesarse por ellas, nos hagan una competencia mortal y sueñen un día echarnos. Serviros del evangelio en los términos de "bienaventurados los pobres porque de ellos es el reino de los cielos" o "le es más difícil a un rico ir al cielo que a un camello entrar en el ojo de una aguja".

Contenerles para evitar que se rebelen. Para eso, enseñarles a soportarlo todo. Comentaréis y les invitaréis a seguir el ejemplo de todos los santos que han puesto la otra mejilla, que han perdonado las ofensas, que han recibido sin inmutarse, escupitajos e insultos...... (Mbocké)

El africano está cosificado y programado para ser un mero instrumento productivo para los intereses occidentales. Permítanme hacer un pequeño inciso. La historia reciente

Revista Iberoamericana, Vol. LXXX, Núms. 248-249, Julio-Diciembre 2014, 1099-1116 ISSN 0034-9631 (Impreso)

ISSN 2154-4794 (Electrónico) 
que nos han transmitido no nos permite aceptar que hace muchos miles de años, el largo cuello de la jirafa era tan corto como el de cualquier cabra, pero que debido a la mutación genética provocada por el esfuerzo físico realizado para lograr su alimento, dicho cuello se alargó hasta alcanzar su actual dimensión y forma, con un cambio de código en el gen responsable del desarrollo de dicho cuello.

Parece que la violencia ejercida contra los africanos desde hace tantos siglos, nos ha hecho sufrir una mutación genética profunda que nos impide volver a nuestras esencias, recuperar o reconstruir nuestro propio imaginario colectivo, y hacer uso del cuarto conocimiento mínimo necesario, la defensa, para poner fin a tanta agresión. Si no fuese así, ¿cómo se explica la falta de soberanía de la que adolece África en los ámbitos político, cultural, lingüístico, religioso, alimentario, militar, económico, etc.? El imaginario colectivo de los africanos parece centrarse principalmente en aspectos meramente locutivos, en relación a términos léxicos como África, Etiopía, Guinea, Nigeria, Sudán, Congo, etc.

\section{¿Descolonizar o Re-DEFiniR NUESTRo IMAGinario COLECTIVo?}

Por todo cuando hemos dicho, entendemos que para descolonizar el Imaginario Colectivo Africano, aparte de centrarnos en:

- la escuela, con la enseñanza de una o dos lenguas interafricanas, de manera que los africanos tengamos una lengua común y evitemos esta dependencia comunicativa hacia las lenguas europeas.

- el comercio y consumo, con la creación de un mercado interafricano, enseñando a los africanos (desde la escuela africana y los medios de comunicación) a consumir preferentemente productos africanos.

- la política africana, con la instauración de una democracia consociativa, de manera que los africanos tengan capacidad de decisión en lo referente a su destino a nivel local, regional, nacional, etc.

- la promoción científica y literaria, con la creación de instituciones interafricanas encargadas de dar validez y reconocimiento internacional africano, primero, y occidental, después, a las obras producidas por africanos. África debe formar parte de la Historia de la Humanidad.

- el reconocimiento social de los héroes (hombres y mujeres) que ha tenido África, para que sirvan como modelos a imitar por los africanos en edad de formación.

Convendría utilizar técnicas científicas muy avanzadas con las que modificar la información que los métodos coloniales parecen haber impregnado en nuestros genes. O sencillamente, reinventar el imaginario colectivo de África, sin miedo y sin traumas, debatiendo como lo estamos haciendo ahora, cómo fue la construcción del africano desde los espacios coloniales, o cómo reconstruir a este africano desde nuestros desastrados

Revista Iberoamericana, Vol. LXXX, Núms. 248-249, Julio-Diciembre 2014, 1099-1116 ISSN 0034-9631 (Impreso)

ISSN 2154-4794 (Electrónico) 
sistemas políticos importados e impuestos. África necesita su propio mundo, y su propio "imaginario colectivo", porque el que tiene ahora, que es del que hablamos ahora, no es nuestro, es de los antiguos colonizadores y de nuestros actuales excolonizadores. Y para el colmo, nuestros gobernantes neocolonizadores viven también con el imaginario colectivo Blanco, porque viven no para gobernar, sino para mantenerse en el poder gracias a los buenos y rentables servicios que prestan a las sociedades occidentales.

Las sociedades blancas, llámense belgas, francesas, portuguesas, inglesas, españolas, etc., han creado unas corrientes de opinión que en su día justificaron la colonización. Fueron corrientes promovidas desde las voces más relevantes de aquellas épocas y desde todos los estamentos, como son:
1. La Iglesia
2. La Política
3. La Enseñanza
4. La Filosofía
5. La Información
6. Etc.

Esta transgresión o transformación de nuestro imaginario colectivo Africano se llevó a cabo desde el poder oficial instituido en nuestros espacios vitales. Hemos visto el ejemplo del discurso de bienvenida del ministro belga Jules Renqin en 1920, y que hemos leído hace un rato. También tenemos la intervención de Cécil Rhodes, Primer Ministro del Cabo (Sudáfrica) en 1898:

Me encontraba ayer en East-End (un barrio obrero londinense) y asistí a una reunión de parados. Escuché discursos desproporcionados. Sólo gritaban una cosa: pan, pan. De regreso a mi casa me convencí mucho más de la importancia del imperialismo... La idea que más me viene a la cabeza es la solución al problema social: para salvar a los cuarenta millones de habitantes del Reino Unido de una guerra civil desastrosa, nosotros los colonizadores tenemos que conquistar nuevas tierras con el fin de instalar en ellas el excedente de nuestra población, para encontrar allí trabajadores para los productos de nuestras fábricas y minas. Como he dicho siempre, el Imperio es una cosa de estómago. Si se quiere evitar la guerra civil, hay que hacerse imperialista.

O las palabras de Rondet-Saint, recogidas en La Dépêche Coloniale en 1929:

No hay que cansarse de repetirlo: la colonización no es una intervención filosófica ni un gesto sentimental. Sea para nosotros o para cualquier otro país, es un asunto de negocios. Más aún, un asunto que exige dedicación, dinero, sacrificios, etc., que se justifican con la remuneración. (Mbocké)

Revista Iberoamericana, Vol. LXXX, Núms. 248-249, Julio-Diciembre 2014, 1099-1116 ISSN 0034-9631 (Impreso) 
También la religión ha contribuido enormemente en esta transgresión y violencia hacia nuestro imaginario colectivo africano. Tenemos, como ejemplo, el extracto de la Bula papal del Papa Nicolás V, en enero de 1454:

Antaño concedimos al Rey Alfonso, entre otras cosas, la plena y total facultad de atacar, conquistar, vencer, reducir y someter a los negros, paganos y otros enemigos de Cristo donde quiera que estén, con sus reinos, ducados, principados, dominios, propiedades, muebles e inmuebles, todos los bienes poseídos, de reducir a la servidumbre a perpetuidad.... (Mbocké)

Todas las citas anteriores nos dan una idea aproximada de cómo procedieron los colonizadores para destruir en tan poco tiempo, el imaginario colectivo africano.

\section{¿IMAGINARIO COLECTIVO O ABISMO INTERAFRICANO?}

Tal como han podido comprobar, la justificación de la colonización, o de la agresión, la explotación, la ocupación del espacio negro por parte de los blancos se encuentra en el poder, sea religioso, político, intelectual, etc. El año pasado (2008) el Premio Nóbel de Medicina James Watson decía que los negros éramos menos inteligentes que los blancos. Hubo muchas voces discrepantes. Pero el mensaje llegó a todas partes. No hubo una reacción contundente ni por parte de los políticos africanos ni por parte de la misma Academia Sueca. Con este tipo de conductas, difícilmente podremos hablar de la descolonización del imaginario colectivo de África, porque es algo construido y mantenido desde Occidente. Y sobre todo porque somos productores y consumidores de dos tipos de literaturas:

1. La de los vencedores y ganadores.

2. La de los vencidos y perdedores, que busca su reconocimiento, y por tanto, no puede enfrentarse a sus valedores.

Los promotores y autores de la primera han impuesto y transmitido los nombres de aquellos personajes o héroes oficiales para que no sean jamás olvidados. Nos referimos a los exploradores, a los gobernadores generales, a los inventores, etc. Estos promotores y autores tampoco reconocerán la literatura de los productores de la segunda, mientras ésta no sea valorada ni reconocida por sus dueños. Nuestro "imaginario colectivo" se mueve en esta doble crisis: la impuesta por los ganadores occidentales y que lleva irremediablemente a la desetnización de nuestras sociedades, y la promovida desde nuestros propios gobernantes y que también nos lleva a la desetnización y patrimonialización del Estado. La parte mágica de nuestra memoria ha sido conformada con sueños ajenos a nuestras realidades.

Revista Iberoamericana, Vol. LXXX, Núms. 248-249, Julio-Diciembre 2014, 1099-1116 ISSN 0034-9631 (Impreso)

ISSN 2154-4794 (Electrónico) 
La occidentalización de nuestro imaginario colectivo nos ha sumido en una profunda confusión identitaria, y nos ha situado en el espacio del desconcierto, la desterritorialidad socioemocional, etc., y en el que se imponen dos únicas salidas: la imperativa búsqueda de una identidad o la necesaria aceptación del creciente grupo desidentificado.

Unas cosas tan sencillas como veladas narrativas en las aldeas africanas y en lenguas autóctonas, unos talleres de lectura crítica de obras producidas por autores africanos (o africanistas), una presentación y comentario de estas obras por parte de sus estudiosos y ante un público no instruido, sería de gran ayuda para la construcción de un pensamiento panafricano "globalizado"; o una presencia regular de las realidades africanas como materias obligadas en las escuelas vernacularizadas, etc., serían de gran utilidad para la construcción y descolonización de este imaginario colectivo de África.

Tampoco debemos pasar por alto el papel de los medios de comunicación, cuya importancia en la reconstrucción del imaginario africano culturalmente realfabetizado (o reculturizado) resulta francamente indispensable en esta era de la cibernética mundial, aprovechando sus múltiples ventajas y sin que estén en manos de nuestros gobernantes destructores o depredadores.

\section{LLEGAMOS A LA CONCLUSIÓN}

Las relaciones humanas se establecen según tres criterios:

1. La atracción (manifestada con el ya clásico flechazo de los protagonistas).

2. La proximidad (o cercanía de los implicados, es decir, los encuentros fortuitos en el barrio, en el trabajo, en algún medio de transporte, etc.).

3. La afinidad o el hecho de tener muchas o algunas coincidencias (desde temas comunes, ocio, gustos, etc., hasta temas específicos).

Pero yo añado un cuarto criterio, el del dominio, que también podemos denominar poder condigno (la sumisión pura y dura) que los colonizadores practicaron con los colonizados africanos, y que más tarde daría lugar a la aparición del síndrome de Estocolmo en los afectados.

Las experiencias obligadas y comunes que hemos vivido los africanos por medio de los procesos de aculturación, inculturación, desracialización, etc., han fortalecido en nosotros vínculos transversales contrarios a nuestras propias realidades. Si hablamos -y de hecho es así- lenguas europeas para comunicarnos entre nosotros, si nuestras conciencias están construidas según los modelos europeos, si tenemos una dependencia absoluta hacia lo que nos han enseñado, etc., es hasta cierto punto normal que actuemos como europeos, reneguemos de nuestra esencia y nos identifiquemos más con nuestros opresores que son, a fin de cuentas, los maestros o diseñadores de nuestras conciencias. 
Después de tantos siglos de absoluta dominación blanca y de desastre gubernamental negro, después de la construcción e imposición de un mundo culturalmente (y casi genéticamente) homogeneizado (el mundo cristiano) y dominante, hablar de un imaginario colectivo africano o guineoecuatoriano se puede hacer desde tres parámetros: primero, los occidentales, ya que los espacios de enculturación reservados a los africanos no incluyen programas pensados y creados por nosotros. Segundo, los africanos, cuyos referentes y elementos identitarios están por reinventar, reordenar o redefinir debido a la confusión reinante. En resumidas cuentas, nuestro imaginario está por reconstruir o rediseñar. Tercero, la indefinición de nuestro imaginario colectivo como guineoecuatorianos nos condena a una irremediable levedad. Habría que insistir en este aspecto concreto de nuestra definición, es decir, en la necesaria construcción de nuestro imaginario específico, con nuestros propios elementos culturales, para después inventariar aquellos elementos compartidos entre todos y cada uno de los Estados diseñados para nosotros. Todo debe hacerse sin ligereza, buscando reimplantar las soberanías colectivas precoloniales, a sabiendas que estamos en contextos distintos englobados dentro de la poscolonialidad. Al contemplar nuestro presente, nos viene a la mente la imperiosa necesidad de contrastar a los dos tipos de africanos que conocemos hoy, siempre desde los procesos de enculturación, ya sea diglósica o normal:

\begin{tabular}{|l|l|}
\hline ICA-Enculturación Autóctona & ICA-Enculturación Pre/Poscolonial \\
\hline & Dios. \\
Dios/es (o no Dios/es). & Ángeles y difuntos. \\
Espíritus y antepasados. & Médicos, brujos, videntes, etc. \\
Curanderos, hechiceros, adivinos, & Lenguas oficiales de relación. \\
etc. & Industria general (tecnológica, textil, \\
Lenguas autóctonas. & alimenticia, etc.). \\
Artesanía funcional (cestas, aros, & Cuentos y dibujos animados (el mago de oz, \\
hachas, etc.). & la cenicienta, Mickey Mouse, Blancanieves \\
Fronteras geográficas sin delimitar. & y los siete enanitos, etc.). \\
Producción agraria y pesquera de & Iniciación escolar. \\
auto-subsistencia. & Ocio y tiempo libre. \\
Cuentos y leyendas africanas. & Juegos olímpicos. \\
Períodos iniciáticos. & Música individualista. \\
Manifestaciones culturales (fiestas, & Naves espaciales, aviones, satélites, etc. \\
eventos sociales, etc.). & Computadoras e Internet. \\
Canciones populares y romanzas. & Radio-televisión y periodistas. \\
Tam-tam y griots. & Fronteras geográficas delimitadas por los \\
Existencia de pueblos-nación, o & europeos. \\
etnias-nación. & Nombres y gentilicios acuñados por los \\
Trabajos comunitarios. & europeos. \\
Ceremonias y ritos colectivos. & \\
& \\
\hline
\end{tabular}

Revista Iberoamericana, Vol. LXXX, Núms. 248-249, Julio-Diciembre 2014, 1099-1116 ISSN 0034-9631 (Impreso)

ISSN 2154-4794 (Electrónico) 
Podríamos seguir comparando ambos contextos hasta disponer de una larga lista de contrastes. Pero vamos a detenernos aquí. Sin embargo, permítanme decir que para tener éxito en la descolonización de nuestro imaginario colectivo como guineoecuatorianos o como africanos, tendríamos que "africanizar" o "vernacularizar" nuestras escuelas, nuestras lenguas oficiales, nuestros sistemas políticos, nuestro sistema de producción, etc. No tenemos más que observar lo que pasa en las aulas en África para darnos cuenta del daño etno-cultural que la escuela ha causado (y causa todavía) en las jóvenes generaciones. Tendríamos que ser realmente soberanos.

\section{OBRAS CITADAS}

Ghalioun, Burhan. "Globalización, deculturación y crisis de identidad”. Cidob d'afers internacionals (diciembre 1998-enero 1999): 43-44.

Gnahoui,Aurélien. "Égypte antique etAfrique noire: une parentée méconnue et occultée" $(2008)<$ www.afrology.com/soc/egypte_afrique.html>. 27 marzo 2008.

Gutiérrez Azopardo, Ildefonso. "Los papas en los inicios de la trata negrera" (2013) $<$ http://www.nedobandam.com/wp-content/uploads/2013/06/Los-Papas-en-losinicios-de-la-Trata-Negrera.pdf>. 14 junio 2014.

Kesteloot, Lilyan. Histoire de la littérature negro-africaine. Paris: Karthala-Auf, 2001.

Mbocké, Sylvia. Le rôle des missionnaires à l'époque coloniale? (2005) < http://www. bonaberi.com/article.php?aid=1520>. 15 junio 2014.

Ngandou Nkashama, P. Comprendre la littérature africaine écrite en langue française. La poésie, le roman, le théâtre. Issy les Moulineaux: Éditions Saint-Paul, 1979.

Rhodes, Cecil. "Carta al periodista Stead" (1895) <https://sites.google.com/site/ eportafoliodeapoyoccss4oeso/tema-6-la-epoca-del-imperialismo>. 14 junio 2014.

Thiong'o, Ngugi wa. Decolonising the Mind: The Politics of Language in African Literature. London: James Currey, 1986.

Tylor, Edward. La civilisation primitive. Mme Pauline Brunet, trad. Paris: Reinwald, 1876. 